\title{
FITORREMEDIAÇÃO DE ÁREAS CONTAMINADAS POR REJEITO DE MINERAÇÃO: AVALIAÇÃO DAS CONCENTRAÇÕES DE FERRO E ZINCO - ESTUDO DE CASO DE BENTO RODRIGUES, MARIANA, MG
}

Cláudia Campos de Albuquerque - claudiacalbuquerque1@gmail.com CEFET - MG

Pedro Augusto Pereira Guedes - pedroguedesbh25@gmail.com CEFET - MG

Mariana Martins Drumond - mmdrumond@deii.cefetmg.br CEFET - MG 


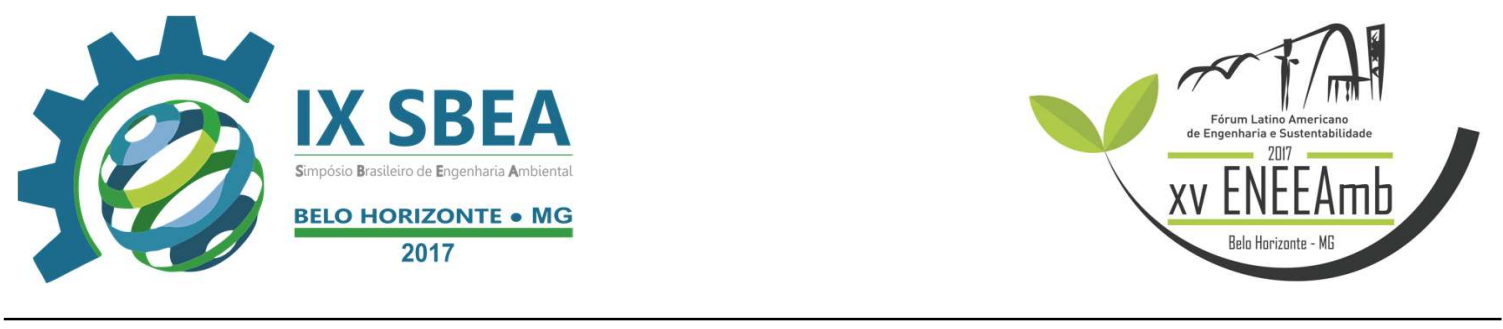

\section{RESUMO}

Os estudos sobre técnicas viáveis para a remediação dos impactos ambientais em Bento Rodrigues - MG, após o rompimento da barragem do Fundão, que era localizada neste subdistrito, ainda são poucos. O presente trabalho avalia a contaminação do solo desse local por metais pesados e a fitorremediação como diferentes espécies como forma de remoção destes, utilizando a espectrometria de absorção atômica como método para a análise do solo inicial e após a remediação. Os metais analisados foram ferro e zinco e as plantas utilizadas foram alface lisa (Lactuca sativa), milho (Zea mays), feijão (Phaseolus vulgaris L.) e grama bermuda (Cynodon dactylon). Também foi avaliada a capacidade de translocação dos metais estudados nessas espécies vegetais. A concentração de metais no solo inicialmente mostrou-se muito acima dos valores reportados para o local antes do rompimento da barragem. $\mathrm{O}$ ferro não apresentou grandes diferenças em sua concentração enquanto a do zinco foi reduzida consideravelmente. A translocação foi avaliada em diferentes partes dos vegetais (raiz, caule e folhas) e os resultados encontrados demonstram que cada grupo apresenta um padrão de acumulação diferenciada.

Palavras-chave: solo, rejeito de mineração, translocação, remediação, ferro, zinco, Bento Rodrigues.

\section{INTRODUÇÃO/OBJETIVO}

A atividade mineradora é de extrema importância para a economia de diversos países, pois é fonte de emprego e renda, além de ser essencial como fornecedora de matéria prima para diversos setores da indústria. (FARIAS, 2002). Com o aumento de sua intensidade nos últimos anos devido ao crescimento populacional, ao avanço da tecnologia e a consequente demanda por matéria prima, os impactos causados por suas atividades, bem como o consumo de seus produtos finais, chamaram a atenção de muitos pesquisadores e causaram muita polêmica (SILVA, 2007).

Devido a esse aumento, houve a necessidade de se dispor em algum local, aqueles resíduos provenientes do processo produtivo e de beneficiamento do minério, que são chamados de rejeitos de mineração. Dessa forma, com o intuito de diminuir os 


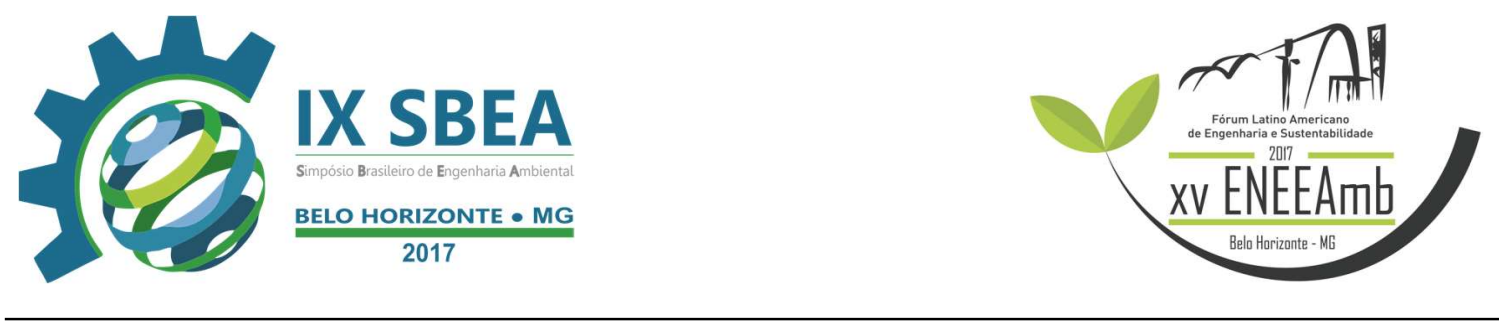

gastos e resolver problemática dos rejeitos, muitas mineradoras veem as barragens, como uma alternativa para essa disposição (SOUZA \& SANTOS, 2015).

A barragem do Fundão, é uma barragem de contensão de rejeitos de mineração, administrada pela empresa Samarco Mineração S.A e, em novembro de 2015, essa barragem se rompeu, destruindo o subdistrito de Bento Rodrigues-MG, levando 19 pessoas ao óbito, desalojando centenas de famílias e causando um desastre ambiental incalculável.

Segundo o Laudo Técnico Preliminar, realizado pelo IBAMA, um dos maiores impactos causados pelo derramamento da lama proveniente do rompimento da barragem foi a disposição de metais tóxicos no solo, sendo que, dentre os metais listados pelo laudo, estão: Cádmio (Cd), Níquel $(\mathrm{Ni})$, Cromo $(\mathrm{Cr})$, Cobalto $(\mathrm{Co})$, Mercúrio $(\mathrm{Hg})$, Manganês (Mn), Vanádio (V), Zinco (Zn), Arsênio (As), Chumbo (Pb), Cobre $(\mathrm{Cu})$, Lítio (Li) (IBAMA, 2015).

Os metais pesados, quando em concentrações elevadas, podem causar sérios danos aos organismos vivos (GOYER, 1996 apud MUNIZ \& OLIVEIRA-FILHO, 2006) e, o aumento de sua concentração no solo faz com que este torne-se contaminado e, consequentemente impróprio para uma série de atividades. (ABNT, 1989).

Dessa forma, com a contaminação eminente, é necessário que se tomem medidas para a remediação desse solo. Uma alternativa para esse processo é utilização de organismos fitorremediadores para a descontaminação do local. Esse processo ocorre in situ e consiste na utilização de plantas e microrganismos a fim de que através de seus processos metabólicos os metais pesados sejam removidos, absorvidos, transferidos e estabilizados, tornando-se inofensivos (LAMEGO \& VIDAL, 2007).

Diante do exposto, o presente trabalho tem como objetivo avaliar a capacidade de fitorremediação, do solo contaminado pelo derramamento do rejeito de mineração proveniente do rompimento da barragem do Fundão, em Bento Rodrigues-MG, no que concerne às fitoextração de ferro e zinco, bem como avaliar o processo de translocação dos referidos metais nos diferentes vegetais estudados.

\section{METODOLOGIA}




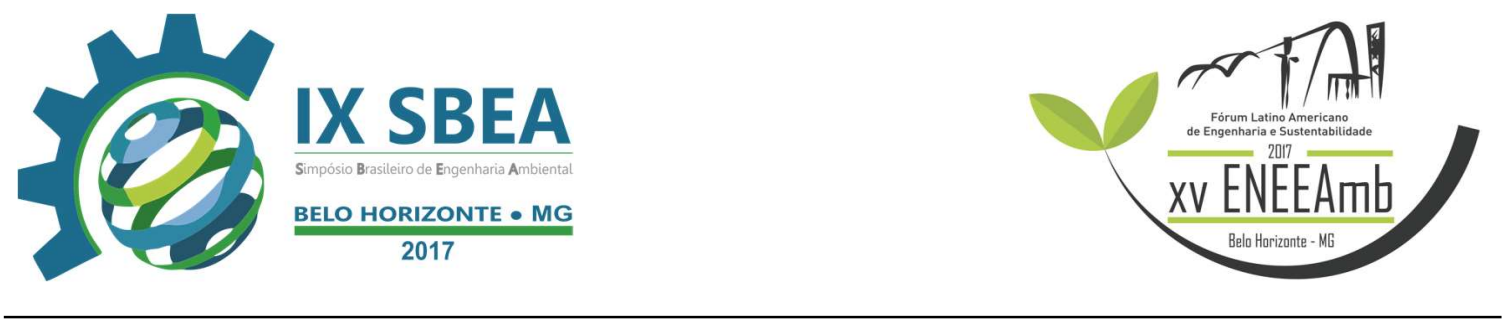

Coletou-se, em março de 2016, aproximadamente $0,2 \mathrm{~m}^{3}$ de solo proveniente da área acometida pelo derramamento de rejeitos de mineração (20¹4'21.30"S e $43^{\circ} 25^{\prime} 17.70^{\prime \prime}$ ), no subdistrito de Bento Rodrigues, Mariana/MG. O solo foi coletado em um mesmo ponto (Figura 1), em uma área de abrangência de aproximadamente 4,0 $\mathrm{m}^{2}$.

A coleta foi realizada em uma área relativamente plana, tendo apenas vegetação rasteira nativa. A coleta foi realizada com pá e o material foi acondicionado em baldes previamente higienizados. Todo o procedimento de coleta seguiu o protocolo indicado por Squiba, et al. (2002).

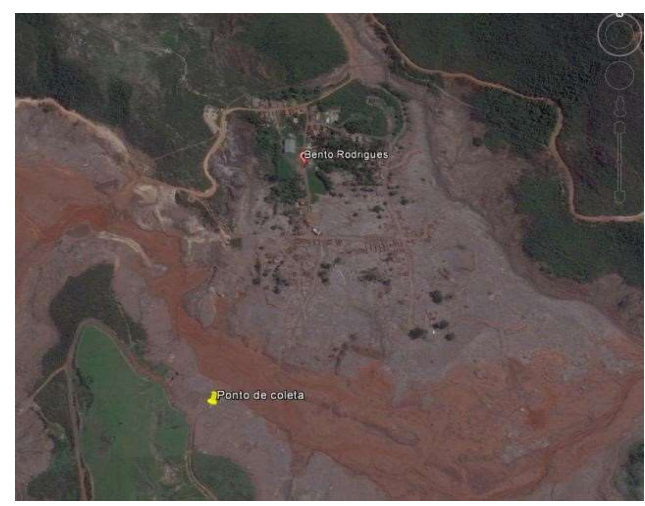

Figura 1: Ponto de coleta do solo. A marcação em amarelo mostra a área onde o solo foi coletado. Fonte: Google Earth.

O material coletado foi transportado até o local de condução do experimento (campus do CEFET/MG), onde foi homogeneizado. Posteriormente, foi disposto igualmente em 7 recipientes de $0,01 \mathrm{~m}^{3}$, previamente forrados com lona impermeável para evitar qualquer tipo de contaminação.

Amostras foram retiradas do solo já homogeneizado, secas e submetidas a análises para a quantificação de Ferro $(\mathrm{Fe})$ e Zinco $(\mathrm{Zn})$, realizadas através da Espectrometria de Absorção Atômica com chama nos laboratórios do CEFET -MG.

Avaliou-se a concentração de matéria orgânica de cada uma das amostras, através do método de Walkley-Black, como proposto por Leite et al (2003). Com os resultados dessa análise preliminar, foi necessária a realização de um tratamento preliminar com a incorporação de matéria orgânica às amostras. 


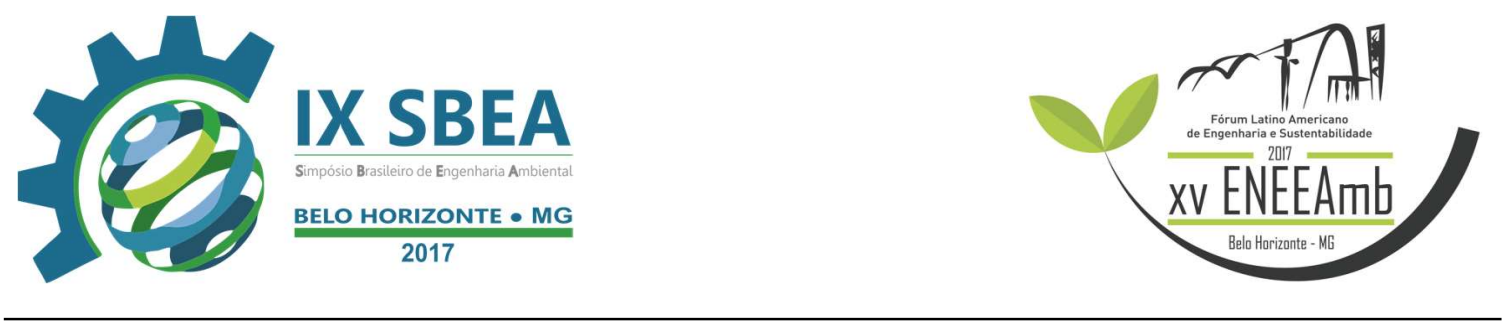

O processo de incorporação de matéria orgânica consistiu em adicionar 850gr de esterco de curral a cada um dos recipientes à exceção de um, que serviu como controle. Seguiu-se, para esta etapa, o procedimento adotado por Neto (2005). Após a incorporação da matéria orgânica, aguardou-se um período de dez dias antes da realização do plantio dos vegetais.

Durante todo o experimento fez-se a determinação do $\mathrm{pH}$ das amostras, seguindo a metodologia proposta pela EMBRAPA (1997) e as estimativas de CTC foram calculadas conforme proposto por Keng \& Uehara (1974), a partir dos resultados de pH.

Aguardado o prazo de 10 dias para assimilação da matéria orgânica, foi realizado o plantio das seguintes espécies: alface lisa (Lactuca sativa), milho (Zea mays), feijão (Phaseolus vulgaris L.) e grama bermuda (Cynodon dactylon), nos recipientes com o solo coletado e matéria orgânica incorporada. A escolha dessas espécies se baseou em sua capacidade de bioacumulação dos metais, descritas por Melo et al (2004).

Em um dos recipientes, todas essas espécies foram plantadas em conjunto, e ainda houveram dois experimentos controle, um apenas com a matéria orgânica incorporada no solo e outro apenas com o solo coletado, sem nenhum tipo de incorporação exógena. O plantio foi realizado de acordo com as instruções fornecidas pelos fornecedores das sementes.

Diariamente, durante todo o experimento, os recipientes foram irrigados, com 1 L de água (exceto nos dias de chuva), de acordo com a metodologia empregada por Simão (1956).

A retirada dos vegetais para as análises de concentração de ferro e zinco, ocorreu em junho de 2016, aproximadamente 45 dias após o plantio inicial. Neste mesmo momento também se coletou amostras de solo de cada um dos tratamentos avaliados. Todas as avaliações foram realizadas através da técnica de Espectrometria de Absorção Atômica com chama, realizada no Laboratório 417 do Centro Federal de Educação Tecnológica de Minas Gerais (CEFET/MG).

\section{RESULTADOS E DISCUSSÃO}




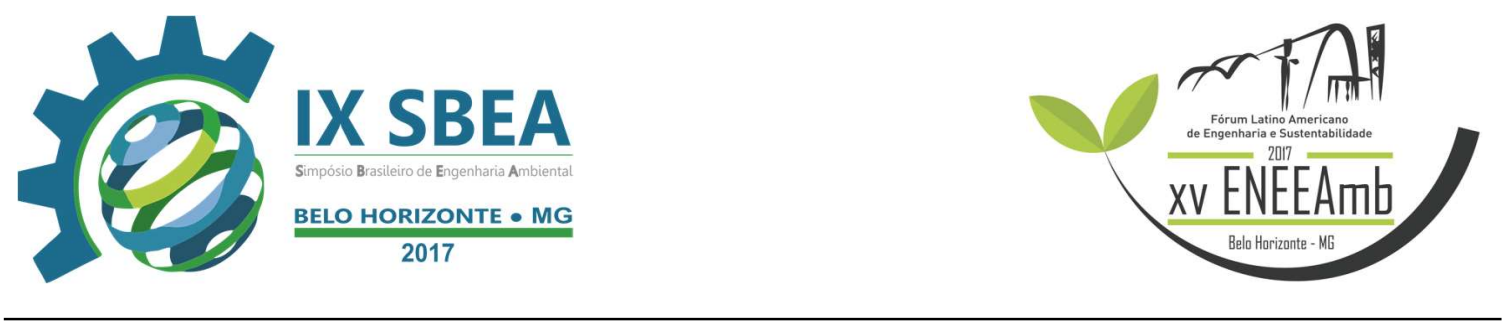

Os metais pesados, apesar de muitos terem funções biológicas importantes, quando se encontram em quantidades maiores podem se tornar um problema muito grave à vida do local contaminado (CARNEIRO et al., 2001). Devido ao potencial fitotóxico desses metais, eles podem influenciar diretamente no crescimento vegetal, substituindo nutrientes essenciais ao desenvolvimento da planta, podendo dessa forma, levar populações mais sensíveis a esses metais à extinção (SOARES et al., 2001).

A tabela 1 mostra os resultados encontrados quanto à concentração de matéria orgânica nas amostras de solo antes e após a incorporação de matéria orgânica.

Tabela 1: Valores da concentração de Matéria Orgânica das amostras de solo coletadas em Bento Rodrigues, Mariana, MG, antes e após a incorporação de matéria orgânica.

\begin{tabular}{|l|c|}
\hline \multicolumn{1}{|c|}{ Solo } & Concentração (g.kg- ${ }^{1}$ ) \\
\hline $\begin{array}{l}\text { Sem incorporação de Matéria } \\
\text { Orgânica }\end{array}$ & 1,914 \\
\hline $\begin{array}{l}\text { Com incorporação de Matéria } \\
\text { tratamento }\end{array}$ & 3,862 \\
\hline
\end{tabular}

O valor de matéria orgânica encontrada na análise do solo de Bento Rodrigues foi baixo, conforme esperado, uma vez que, segundo Santos et al. (2010), a composição do rejeito de mineração é basicamente sílica e metais, com poucos nutrientes e pouca matéria orgânica.

A incorporação de matéria orgânica levou a um incremento de quase $100 \%$ na concentração quando comparado à amostra que não sofreu o processo de incorporação. Adicionalmente, pode-se observar que não houve qualquer tipo de crescimento vegetal no grupo controle, em que não houve incorporação de matéria orgânica, enquanto no controle em que houve incorporação, alguns vegetais cresceram, como demonstrado pela figura 2 (A e B).

A germinação de vegetais no grupo controle em que houve a incorporação de matéria orgânica mostra a importância da presença de compostos orgânicos no solo que atuam favorecendo o crescimento vegetal, seja através da disponibilidade de nutrientes ou pelo aumento da porosidade do solo, possibilitando uma maior retenção de água e nutrientes (DINIZ et al, 2008). 

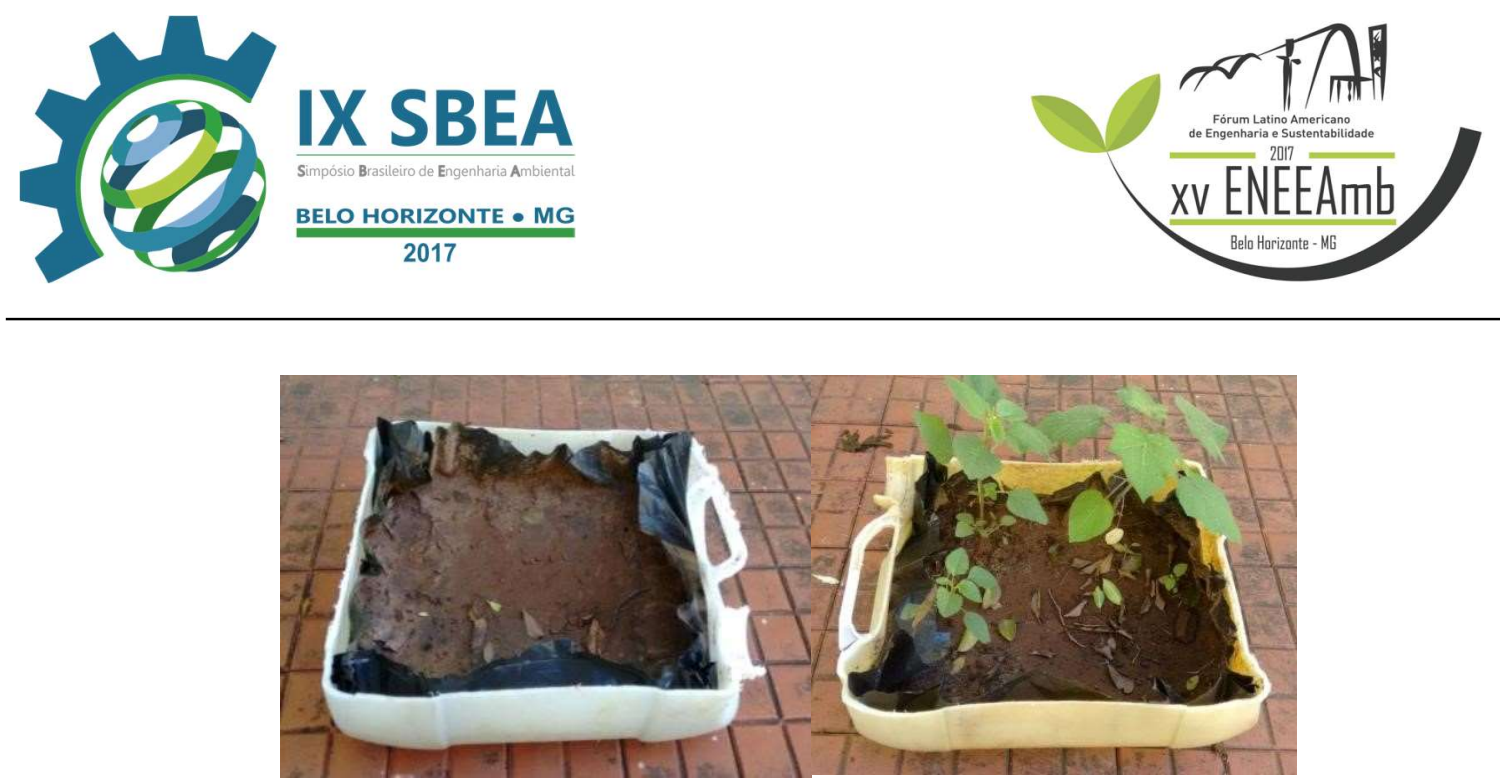

Figura 2: Parcelas experimetais dos grupos controles. ANegativo, em que não se incorporou matéria orgânica, Bpositivo, com imcorporação de matéria orgânica.

A tabela 2 mostra os resultados encontrados nas análises de $\mathrm{pH}$ do solo contaminado pelos rejeitos de mineração.

Tabela 2: Valores de $\mathrm{pH}$ das amostras de solo coletadas em Bento Rodrigues, Mariana, MG, com duas diferentes técnicas: água destilada e Cloreto de potássio $(\mathrm{KCl})$.

\begin{tabular}{|c|c|}
\hline Técnica & pH médio \\
\hline Água destilada & 8,67 \\
\hline $\mathrm{KCl}$ & 6,50 \\
\hline
\end{tabular}

Com os valores encontrados na análise de $\mathrm{pH}$ é possível calcular a variação de $\mathrm{pH}$, que se baseia no cálculo deste parâmetro em $\mathrm{KCl}$ menos o valor encontrado para o mesmo em água destilada. O módulo do valor encontrado representa a capacidade de troca de cátions (CTC) do solo. Esse valor foi de 2,17 que pode ser considerado um valor alto, significando que esse solo possui boa capacidade de retenção de cátions (FRAZÃO et al., 2008).

Segundo Souza (2015), 49,06\% do solo no entorno da bacia do Rio Doce é composta por Latossolo Vermelho Amarelo, sendo o solo do subdistrito de Bento Rodrigues, um exemplo desse tipo. Segundo Fadigas et al (2006), solos deste tipo, sob a condição de mínima ou nenhuma atividade antrópica, apresentam concentrações de 20900 e 25 mg. $\mathrm{kg}^{1}$ para os metais ferro e zinco, respectivamente. Com relação à análise inicial desses metais pesados avaliados no presente estudo, os resultados estão apresentados na tabela 3 . 


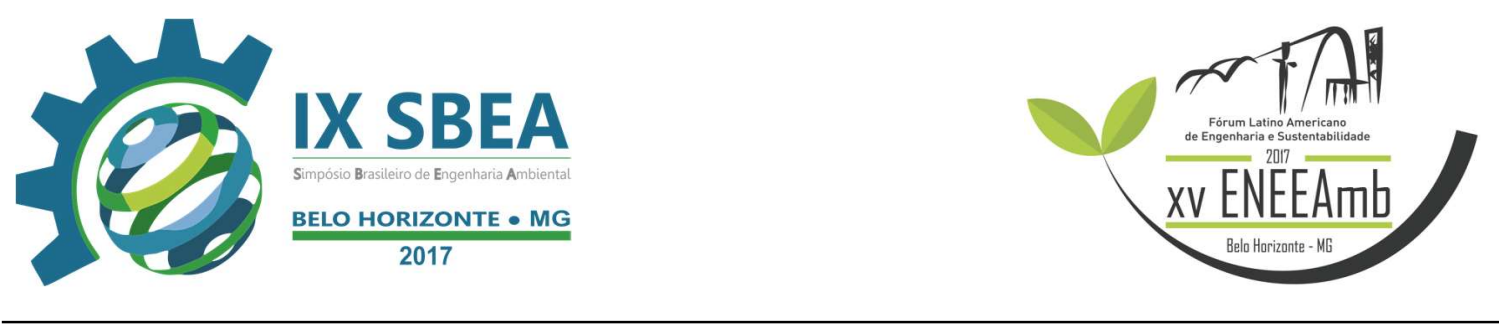

Tabela 3: Concentração dos metais pesados ferro $(\mathrm{Fe})$ e zinco $(\mathrm{Zn})$ encontrados nas amostras de solo coletadas em Bento Rodrigues, Mariana, MG.

\begin{tabular}{|c|c|}
\hline Metal & Concentração (mg.kg- ${ }^{\mathbf{1}}$ ) \\
\hline Ferro $(\mathrm{Fe})$ & 50185,19 \\
\hline Zinco $(\mathrm{Zn})$ & 286,03 \\
\hline
\end{tabular}

Pode-se perceber uma grande diferença nas concentrações dos metais pesados em um mesmo tipo de solo, antes e após a ação antrópica. Essa elevada carga de metais encontrados já era esperada devido ao lançamento dos rejeitos de mineração no solo após o rompimento da barragem de Fundão, e esse aumento pode causar desequilíbrios nos ecossistemas, devido à toxidade desses metais.

Para o ferro (Fe), Kuki et al (2009) observaram sintomas de toxidade em algumas plantas em solos com altos teores desse metal. Alguns desses sintomas estão relacionados ao desenvolvimento de raízes recobertas por placas de ferro e atrofia no crescimento além do aparecimento de manchas avermelhadas na superfície do vegetal.

Segundo Carneiro et al. (2002), solos com altos teores de zinco ( $\mathrm{Zn}$ ), podem ser potencialmente tóxicos para plantas, causando necrose de suas partes aéreas e inibindo significativamente seu crescimento.

Após o processo de fitorremediação, os valores encontrados para o metal pesado ferro $(\mathrm{Fe})$ estão apresentados na tabela 4.

Tabela 4: Valores da concentração de ferro $(\mathrm{Fe})$ das amostras de solo coletadas em Bento Rodrigues, Mariana, MG, após o processo de fitorremediação com diferentes vegetais.

\begin{tabular}{|c|c|}
\hline Amostra & Concentração média $\left(\mathrm{mg}^{\mathrm{kg}} \mathrm{kg}^{-1}\right)$ \\
\hline Controle Positivo $^{1}$ & 50493 \\
\hline Controle Negativo $^{2}$ & 50767 \\
\hline Solo com alface & 50658 \\
\hline Solo com feijão & 49078 \\
\hline Solo com grama & 50185 \\
\hline Solo com milho & 49427 \\
\hline $\begin{array}{c}\text { Solo com todas as } \\
\text { plantas }\end{array}$ & 50767 \\
\hline
\end{tabular}

${ }^{1}$ - Solo com incorporação de Matéria Orgânica

2- Solo sem incorporação de Matéria Orgânica

Pode-se perceber que o teor de ferro no solo não alterou significativamente, e isso pode estar associado à presença desse metal em sua forma de óxido, não estando assim biodisponível para absorção das plantas. Observou-se absorção de ferro por todos 


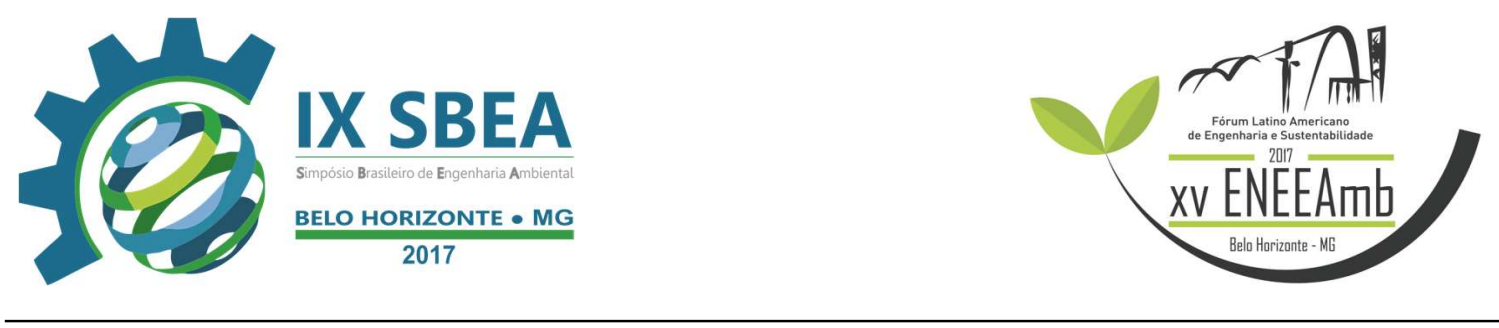

os vegetais avaliados no experimento e, uma maior concentração nas raízes testadas oriundas solo contaminado. $\mathrm{O}$ ferro é um micronutriente necessário para o desenvolvimento das plantas e sua presença no tecido vegetal já é esperada. Os resultados das análises de translocação do ferro nas diferentes partes dos vegetais estudados no presente estudo estão demonstrados na Tabela 5.

Tabela 5: Valores da concentração de ferro (Fe) nos diferentes órgãos dos vegetais avaliados utilizados no processo de fitorremediação do solo de Bento Rodrigues, Mariana, MG.

\begin{tabular}{|c|c|c|c|c|c|c|c|c|c|c|c|c|}
\hline \multirow[t]{3}{*}{ Amostra } & \multicolumn{12}{|c|}{ Vegetal / órgão analisado - Concentração de $\mathrm{Fe}\left(\mathrm{mg} . \mathrm{kg}^{-1}\right)$} \\
\hline & \multicolumn{3}{|c|}{ Alface } & \multicolumn{3}{|c|}{ Grama } & \multicolumn{3}{|c|}{ Feijão } & \multicolumn{3}{|c|}{ Milho } \\
\hline & Raiz & Caule & Folha & Raiz & Caule & Folha & Raiz & Caule & Folha & Raiz & Caule & Folha \\
\hline Solo Normal & & & 224 & $* *$ & $* *$ & ** & 1662 & $* * *$ & 253 & $* * *$ & $* * *$ & 111 \\
\hline $\begin{array}{l}\text { Solo } \\
\text { Contaminado }\end{array}$ & - & - & 10812 & 1678 & - & 3539 & 9268 & 130 & 2689 & 935 & 299 & 738 \\
\hline $\begin{array}{l}\text { Solo com } \\
\text { todos os } \\
\text { vegetais }\end{array}$ & - & - & * & * & - & * & 31221 & 244 & 2480 & $* * *$ & $* * *$ & 334 \\
\hline
\end{tabular}

* As espécies morreram antes do fim do experimento, por isso não houveram amostras para análise.

** Não foi possível obter-se amostras de grama do solo normal.

*** Não se obteve quantidade suficiente, em matéria seca, para a realização das análises.

Foram constatadas algumas concentrações significativas, como no caso da raiz da grama contaminada e do feijão contaminado. O fato da redução deste metal não ter sido significativa em todos os órgãos e nos diferentes tipos de solo analisados pode ser explicada, pelo menos em parte, pela metodologia empregada nas análises, que utiliza a matéria seca vegetal para determinação da concentração dos metais pesados. O processo de secagem concentra o elemento e encontra respaldo no trabalho de Pimentel (2004), que menciona a composição celular de plantas herbáceas, com aproximadamente $90 \%$ de água, que se levado em conta, permitiria a concentração real de ferro em todas as plantas e este seria um valor abaixo do encontrado e pouco significativo.

Com relação às análises finais de solo para o metal zinco $(\mathrm{Zn})$, foram encontrados os valores expostos na Tabela 6: 


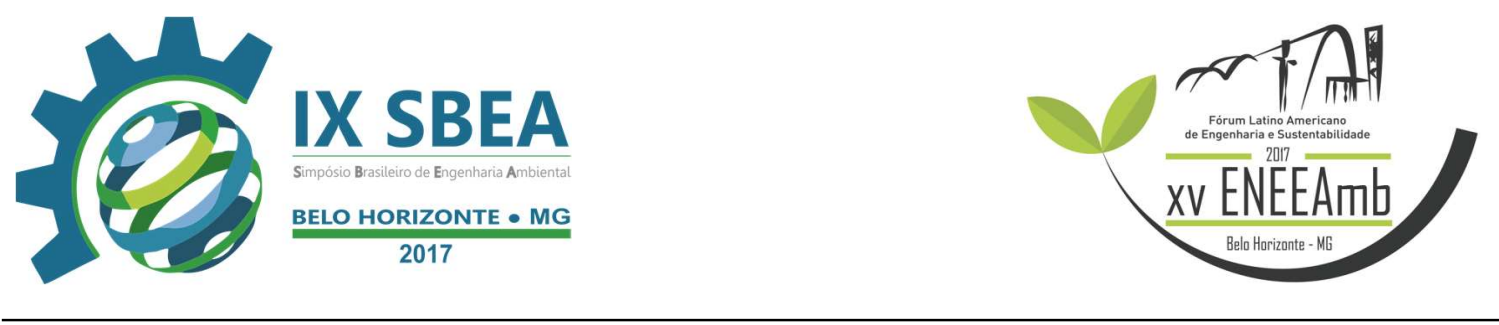

Tabela 6: Valores da concentração de zinco (Zn) das amostras de solo coletadas em Bento Rodrigues, Mariana, MG, após o processo de fitorremediação com diferentes vegetais.

\begin{tabular}{|c|c|}
\hline Amostra & Concentração média $\left(\mathrm{mg}^{\mathrm{kg}} \mathrm{kg}^{-1}\right)$ \\
\hline Controle Positivo $^{1}$ & 261 \\
\hline Controle Negativo $^{2}$ & 269 \\
\hline Solo com alface & 214 \\
\hline Solo com feijão & 234 \\
\hline Solo com grama & 156 \\
\hline Solo com milho & 255 \\
\hline $\begin{array}{c}\text { Solo com todas as } \\
\text { plantas }\end{array}$ & 229 \\
1- Solo com incorporação de Matéria Orgânica \\
2- Solo sem incorporação de Matéria Orgânica \\
\end{tabular}

A partir das concentrações encontradas para este elemento, pode-se perceber uma redução em todas as amostras de solo, na análise realizada ao final do experimento. Este resultado pode estar associado ao fato de o zinco ser um micronutriente essencial para a vida e desenvolvimento das plantas (KIRKBY \& RÖMHELD, 2007) e estar complexado no solo, já que segundo Kabata-Pendias \& Pendias (2001), as formas mais comuns e móveis do Zn são os íons livres e complexados nas soluções do solo, sendo facilmente adsorvido por minerais e compostos orgânicos, havendo maior acúmulo nos horizontes mais superficiais.

Com relação às análises de translocação do zinco pelos diferentes órgãos dos vegetais analisados, os resultados obtidos encontram-se na tabela 7 .

Tabela 7: Valores da concentração de zinco $(\mathrm{Zn})$ nos diferentes órgãos dos vegetais avaliados utilizados no processo de fitorremediação do solo de Bento Rodrigues, Mariana, MG.

\begin{tabular}{|c|c|c|c|c|c|c|c|c|c|c|c|c|}
\hline \multirow[t]{3}{*}{ Amostra } & \multicolumn{12}{|c|}{ Vegetal / órgão analisado - Concentração de Fe $\left(\mathrm{mg} \mathrm{kg}^{-1}\right)$} \\
\hline & \multicolumn{3}{|c|}{ Alface } & \multicolumn{3}{|c|}{ Grama } & \multicolumn{3}{|c|}{ Feijão } & \multicolumn{3}{|c|}{ Milho } \\
\hline & Raiz & Caule & Folha & Raiz & Caule & Folha & Raiz & Caule & Folha & Raiz & Caule & Folha \\
\hline Solo Normal & - & - & 6,15 & $* *$ & $* *$ & $* *$ & 35,5 & $* * *$ & 50,06 & $* * *$ & $* * *$ & 40,11 \\
\hline $\begin{array}{l}\text { Solo } \\
\text { Contaminado }\end{array}$ & - & - & $8^{164,2}$ & $4^{1637,}$ & - & 37,78 & ND & 18,64 & 60,17 & 7,21 & 4,87 & 12,24 \\
\hline $\begin{array}{lr}\text { Solo } & \text { com } \\
\text { todos } & \text { os } \\
\text { vegetais } & \end{array}$ & - & - & * & * & & * & ND & 2,32 & 27,96 & *** & $* * *$ & 16,12 \\
\hline
\end{tabular}

* As espécies morreram antes do fim do experimento, por isso não houveram amostras para análise.

** Não foi possível obter-se amostras de grama do solo normal.

*** Não se obteve quantidade suficiente, em matéria seca, para a realização das análises.

ND - Não detectado pela técnica utilizada. 


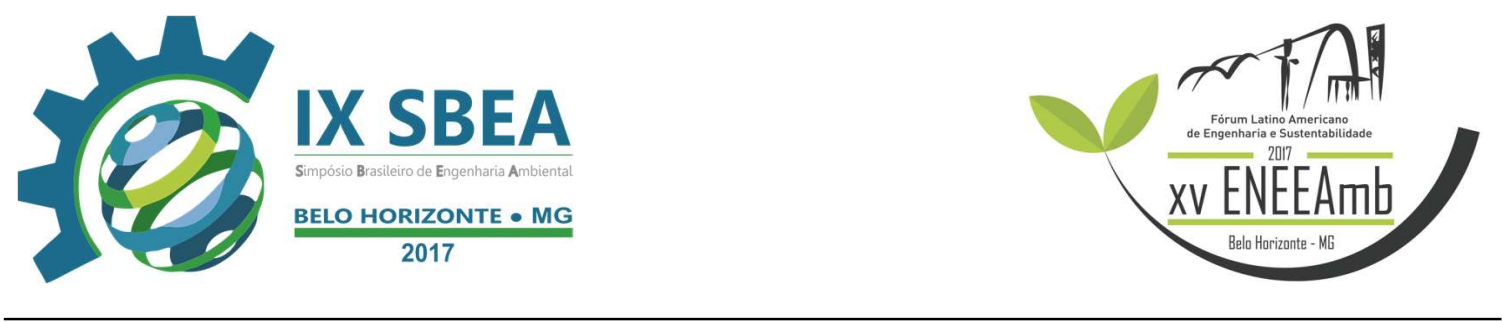

A amostra de solo em que houve a maior redução na concentração de zinco, foi a do recipiente com grama, havendo uma redução de aproximadamente $46 \%$, enquanto a amostra do recipiente com milho, obteve o pior desempenho em relação às outras plantas, contrariando Melo et al (2004), que afirma que a bioacumulação de zinco por parte dessa planta em solos contaminados é alta.

A planta que apresentou uma maior eficiência na translocação do zinco foi o feijão. Na raiz, não foi possível detectar a concentração desse metal, por esse estar em quantidade muito pequena, fora da curva de leitura do equipamento usado na análise. Já nas folhas, a concentração foi mais elevada e possível de ser medida, demonstrando assim, uma eficiente translocação do zinco pelas partes do feijão, assim como afirmado por Melo et al. (2004).

\section{CONCLUSÕES/ PERSPECTIVAS}

Em relação ao ferro $(\mathrm{Fe})$, não houve uma variação significativa da concentração nas amostras de solo em nenhum dos recipientes, como já era esperado, já que a maior parte desse metal presente no solo está na forma de óxido, não estando disponível para as plantas.

Já o zinco ( $\mathrm{Zn}$ ), houve diminuição da concentração em todas os recipientes, com destaque para o recipiente com grama, que teve sua concentração diminuída quase pela metade. Em relação às plantas, podemos perceber que o metal zinco, possui uma maior facilidade de translocação pelas partes das plantas, com destaque para o feijão, que possuiu a maior concentração de metais em suas folhas.

Um novo experimento já está sendo conduzido para avaliação da fitorremediação de zinco e cádmio em solos contaminados da mesma área, entretanto utilizando-se diferentes vegetais dos que aqui foram avaliados. A parte experimental in situ já foi realizada e o próximo passo é a finalização das análises laboratoriais. Os resultados parciais obtidos até o momento nos encorajam fortemente a utilizar o processo de fitorremediação como alternativa para melhorar a qualidade de solos contaminados com metais pesados, como é o caso de Bento Rodrigues. 


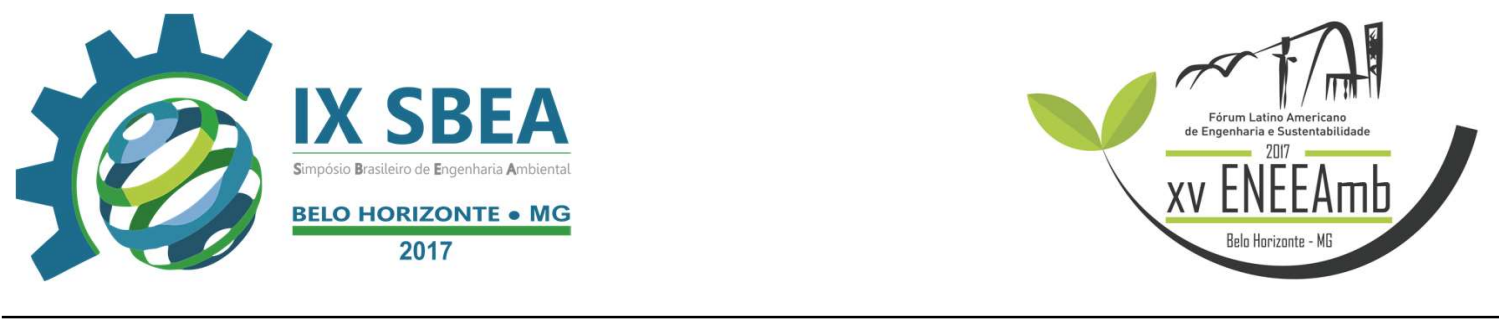

\section{REFERÊNCIAS BIBLIOGRÁFICAS}

ABNT. Degradação do Solo: NBR 10703. 1989. Disponível em: <http://www.ufrgs.br/sga/legislacaoambiental-dowloads-para-links/NBR $10703 \quad 1989$ Degradacao do Solo.pdf>. Acesso em: 30 abr. 2016.

CARNEIRO, Marco Aurélio Carbone; SIQUEIRA, José Oswaldo; MOREIRA, Fátima Maria de Souza. Estabelecimento de plantas herbáceas em solo com contaminação de metais pesados e inoculação de fungos micorrízicos arbusculares. Pesquisa Agropecuária Brasileira, Brasília, v. 36, n. 12, p.1443-1452, dez. 2001. Mensal. Disponível em: <http://www.scielo.br/pdf//pab/v36n12/7486.pdf > . Acesso em: 06 mar. 2017

DINIZ, Ellen Rúbia et al. Crescimento e produção de brócolis em sistema orgânicoem função de doses de composto. Ciência Agrotecnologia, Lavras, v. 32, n. 5, p.1428-1434, set./out. 2008. Disponível em: <https://www.researchgate.net/publicati on/260773533_Growth_and_yield_of_br occoli_on_organic_production_system_a s_a_function_of_compost_dosages $>$. Acesso em: 28 maio 2016.

FADIGAS, Francisco de S. et al. Proposição de valores de referência para a concentração natural de metais pesados em solos brasileiros. Revista Brasileira de Engenharia Agrícola e Ambiental, Campina Grande, v. 10, n. 3, p.699-705, mar. 2006. Disponível em: $<$ http://www.mma.gov.br/port/conama/processos/10F798CF/Doc_PropValores ConcMetaisPesados_SolosBrasileiros.pdf $>$. Acesso em: 15 jun. 2016.

FARIAS, Carlos Eugênio Gomes. Mineração e Meio Ambiente no Brasil. 2002. Disponível em: $<$ http://www.em.ufop.br/ceamb/petamb/cariboost_files/miner_c3_a7_c3_a3o_ 20e_20meio_20ambiente.pdf $>$. Acesso em: 30 maio 2016.

FRAZÃO, Leidivan Almeida et al. Propriedades químicas de um Neossolo Quartzarênico sob diferentes sistemas de manejo no Cerrado mato-grossense. Pesquisa Agropecuária Brasileira, Brasília, v. 43, n. 5, p.641-648, maio 2008. Mensal.

IBAMA, Instituto Brasileiro do Meio Ambiente e dos Recursos Naturais Renováveis -. Laudo Técnico Preliminar: Impactos ambientais decorrentes do desastre envolvendo o rompimento da barragem de Fundão, em Mariana, Minas Gerais. 2015. Disponível em: $<$ http://www.ibama.gov.br/phocadownload/noticias ambientais/laudo tecnico preliminar.pdf $>$. Acesso em: 04 maio 2016.

KABATA-PENDIAS, A.; PENDIAS, H. Trace elements in soils and plants. 3rd ed. Boca Raton: CRC Press, 2001. 413p.

KIRKBY, Ernest Arnold; RÖMHELD, Volker. Micronutrientes na fisiologia de plantas: micronutrientes na fisiologia de plantas: micronutrientes na fisiologia de 

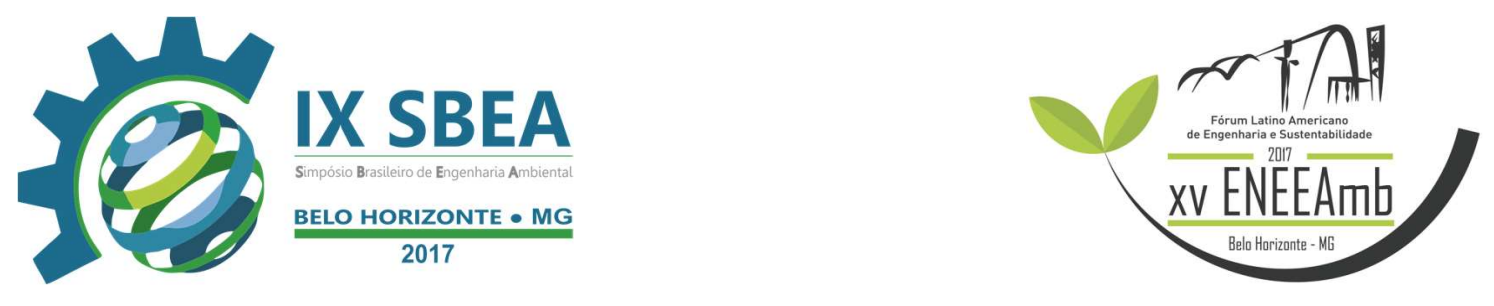

plantas: funções, absorção e mobilidade funções, absorção e mobilidade. 2007. ENCARTE TÉCNICO Nº118.

PIMENTEL, Carlos. A relação da planta com a água. - Seropédica, RJ: Edur, 2004. $191 \mathrm{p}$.

SANTOS, Djanira Alexandra Monteiro dos; CURI, Adilson; SILVA, José Margarida da. Técnicas para a disposição de rejeitos de minério de ferro. 2010. Disponível em: $<$ http://www.cbmina.org.br/media/pale stra 6/T54.pdf $>$. Acesso em: 30 abr. 2016.

SILVA, João Paulo Souza. Impactos ambientais causados por mineração. Revista Espaço da Sophia, Goiás, v. 1, n. 8, nov. 2007. Mensal. Disponível em: $<$ http://www.registro.unesp.br/sites/mu seu/basededados/arquivos/00000429.pd f $>$. Acesso em: 13 jun. 2016.

SIMÃO, Salim. Irrigação de alface. Anais da Escola Superior de Agricultura Luiz de Piracicaba, v. 12-13, p.121-128, 1956. FapUNIFESP SciELO).Disponível em: $<$ http://www.scielo.br/pdf/aesalq/v1213/10.pdf>. Acesso em: 16 abr. 2016.

SOARES, ClÁudio Roberto FonsÊca Sousa et al. ACÚMULO E DISTRIBUIÇÃO DE METAIS PESADOS NAS RAÍZES, CAULE E FOLHAS DE MUDAS DE ÁRVORES EM SOLO CONTAMINADO POR REJEITOS DE INDÚSTRIA DE ZINCO. Departamento de Ciência do Solo, Universidade Federal de Lavras, Cx.P. 37, Lavras, MG, 37200-000. Disponível em: $<$ http://www.scielo.br/pdf/ /rbfv/v13n3/9261.pdf $>$. Acesso em: 04 mar. 2017.

QUEIROZ, Piracicaba, v. 12-13, p.121-128, 1956. FapUNIFESP (SciELO). http://dx.doi.org/10.1590/s007112761956000100015. Disponível $<$ http://www.scielo.br/pdf/aesalq/v1213/10.pdf>. Acesso em: 16 abr. 2016.

em:

SOUZA, Caetano Marciano de. Considerações sobre o rompimento da barragem e solos afetados e comparação do acidente com potencial de erosão na bacia do rio Doce. Viçosa: Ufv, 2015. Color.Disponível em: $<$ http://www2.camara.leg.br/atividadelegislativa/comissoes/comissoestemporarias/exter nas/55alegislatura/rompimento-de-barragem-naregiao-demarianamg/documentos/audienciaspublicas/CaetanoMarcianodeSouzaApres entao15122015.pdf>. Acesso em: 15 jun. 2015.

SOUZA, Maira Jacqueline de; SANTOS FILHO, Nilo Gonçalves dos. Barragens de rejeito. Disponível em: $<$ http://www.faculdadeatenas.edu.br/arquivos/NucleoIniciacaoCiencia/REVISTAJURI 2015/5 BARRAGENS DE REJEITO.PDF>. Acesso em: 08 maio 2016.

SQUIBA, L.M.; MONTE SERRAT, B.; LIMA, M.R. Como coletar corretamente amostras de solos para análises. Curitiba: Universidade Federal do Paraná, Projeto de Extensão Universitária Solo Planta, 2002. (Folder) 